\section{Formation of Volatiles in the Lipoxygenase Pathway as Affected by Fruit Type and Temperature}

Yafei Han and Sheryl Barringer ${ }^{*}$

Department of Food Science and Technology, The Ohio State University, 2015 Fyffe Road, Columbus, OH 43210, USA.

"Correspondence author: Sheryl Barringer, Department of Food Science and Technology, The Ohio State University, 2015 Fyffe Road, Columbus, OH 43210, USA. Tel: 614-688-3642; E-mail: barringer.11@osu.edu

Received date: Sep 16, 2015; Accepted date: Nov 2, 2015; Published date: Nov 9, 2015

Copyright: ( 2015 Han Y, et al. This is an open-access article distributed under the terms of the Creative Commons Attribution License, which permits unrestricted use, distribution, and reproduction in any medium, provided the original author and source are credited.

\begin{abstract}
Objective: The objective of this study is to study the effect of temperature, lipoxygenase activity, substrate and fruit type on formation of volatiles in the LOX pathway.

Methods: Volatiles in the headspace of tomato, bell pepper, tomatillo, strawberry, apple and pear were measured during and after fruit tissue disruption in real time using selected ion flow tube mass spectrometry (SIFT-MS) at 4, 25,37 and $45^{\circ} \mathrm{C}$ for $60 \mathrm{~min}$, and were compared to lipoxygenase (LOX) activity and fatty acid concentration.

Results: In tomatoes, bell peppers and tomatillos, (Z)-3-hexenal, (E)-2-hexenal and hexanal increased rapidly after blending, peaked and declined, while in strawberry, apple and pear they sometimes peaked and sometimes remained constant over the $60 \mathrm{~min}$. In tomato and bell pepper, the peak levels of (Z)-3-hexenal, (E)-2-hexenal and hexanal in the LOX pathway had good correlations to LOX activity, which was greatest at $25^{\circ} \mathrm{C}$. In contrast, tomatillo, strawberry, apple and pear had lower LOX activity, their 6C aldehydes did not show strong correlation with LOX activity, and the volatiles increased with increasing temperature to $45^{\circ} \mathrm{C}$. The concentrations of hexen-1-ol and 1hexanol did not correlate to LOX activity for any of the fruits. In tomato, bell pepper and tomatillo, there was no significant correlation between the ratio of linoleic acid:linolenic and the ratio of hexanal:hexenal. In strawberry, apple and pear, there were good correlations between linolenic acid content and concentrations of (E)-2-hexenal, hexenal and hexen-1-ol.
\end{abstract}

Conclusion: Thus the effect of enzyme activity and substrate composition on formation of volatiles in the lipoxygenase pathway remains complicated and difficult to predict.

Keywords: Lipoxygenase; Temperature; Tomato; Bell pepper; Tomatillo; Strawberry; Apple; Pear; Selected ion flow tube mass spectrometry

\section{Introduction}

As aroma is one of the most important characteristics for fruit quality, volatile compounds are likely to have a huge effect on the perception and liking of fruit products by consumers. In fruits, important aroma compounds are derived from fatty acids, amino acids, phenols and terpenoids [1]. Thus the effect of enzyme activity and substrate composition on formation of volatiles in the lipoxygenase pathway remains complicated and difficult to predict. Among these compounds, volatiles generated from fatty acids via the lipoxygenase (LOX) pathway are responsible for the "green" fresh note, which is desirable in many fruit products [2]. The LOX pathway is an enzymatic pathway for lipid oxidation. The main products of the LOX pathway are C6 aldehydes and alcohols generated through sequential enzymatic reactions. The major enzymes in this pathway include lipoxygenase, hydroperoxide lyase (HPL), alcohol dehydrogenase $(\mathrm{ADH})$ and $(\mathrm{Z})-3 /(\mathrm{E})-2$ isomerase [3]. Linoleic and linolenic acids are the substrates that are converted to volatiles such as hexanal, $(\mathrm{Z})-3$ hexenal, (E)-2-hexenal, 1-hexanol, hexen-1-ol, (E)-2-octenal, (E)-2heptenal, (E)-2-pentenal 1-penten-3-one, hexanoic acid, (Z)-3-hexenyl acetate and hexyl acetate.
Temperature affects the volatile concentrations in the headspace, due to two main factors: different partition coefficients at different temperatures, and different enzymatic activities at different temperatures. The partition coefficient is the ratio between the concentrations of the volatile compound in the gas and liquid phase at equilibrium [4]. The partition coefficient is temperature dependent; the $\log$ value of the partition coefficient is linearly related to the temperature [5]. Temperature also has an effect on activity of enzymes including those involved in the LOX pathway. Tomato LOX activity increases from $0^{\circ} \mathrm{C}$ to $20^{\circ} \mathrm{C}$, reaches its maximum activity at $20^{\circ} \mathrm{C}$ to $30^{\circ} \mathrm{C}$ and decreases at higher temperatures [6,7]. In tomatoes, HPL activity increases from $5^{\circ} \mathrm{C}$ to $25^{\circ} \mathrm{C}$ and decreases from $25^{\circ} \mathrm{C}$ to $40^{\circ} \mathrm{C}$ $[8,9]$. Tomato $\mathrm{ADH}$ activity increases from 10 to $20^{\circ} \mathrm{C}$ and decreases from $20^{\circ} \mathrm{C}$ to $52^{\circ} \mathrm{C}[8,10]$.

Different fruits have different linoleic acid content, linolenic acid content and LOX activity, which may explain different LOX volatile profiles among fruits. When extra linoleic acid was added to tomato homogenates, the hexanal level increased [11]. Similarly, the hexenal level was increased by addition of linolenic acid [11]. The increase of hexanal and 1-hexanol upon addition of linoleic acid and the increase of (Z)-3-hexenal and (E)-2-hexenal upon addition of linolenic acid have been reported in other studies in tomato [12,3], bell pepper [13] and cucumber [14]. When LOX activity in tomato was decreased by reducing expression of LOX mRNA, the levels of hexenal and hexanal 
were significantly decreased [11]. When LOX in bell pepper homogenates was inhibited by 5,8,11,14-eicosatetraynoic acid, the levels of (Z)-3-hexenal, (E)-2-hexenal and hexanal all decreased [13]. The objective of this study is to study the effect of temperature, lipoxygenase activity, substrate and fruit type on formation of volatiles in the LOX pathway.

\section{Material and Methods}

Ripe grape tomatoes, green bell peppers, tomatillos, strawberries, Gala apples and Green Anjou pears were purchased from a local market (Kroger, Columbus, $\mathrm{OH}$, and USA) and stored at room temperature. Fruits were washed and dried. Every replicate consisted of $100 \mathrm{~g}$ fruit and five replicates were tested. To study the effect of temperature and fruit type on volatile generation, samples of the 6 fruits and the blender (3 Cup Chopper, Oster, Boca Raton, FL, USA) were equilibrated in a water bath at $4^{\circ} \mathrm{C}, 25^{\circ} \mathrm{C}, 37^{\circ} \mathrm{C}$ and $45^{\circ} \mathrm{C}$ for $5 \mathrm{~h}$ then attached to the SIFT-MS and kept in a water bath at the corresponding temperature during measurement. To study the effect of blending time on volatile concentration in the headspace, tomato samples were measured at room temperature for each blending time, ranging from 0.5 to $30 \mathrm{~min}$.

\section{Blanching}

To inhibit enzyme activity, $100 \mathrm{~g}$ samples were placed in zip lock plastic bags and submerged in boiling water for $3.5 \mathrm{~min}$. Inactivation was confirmed by testing for peroxidase activity [15].

\section{SIFT-MS}

A plastic tube (length: $95 \mathrm{~mm}$, internal diameter: $8 \mathrm{~mm}$ ) connected the blender to the selected ion flow tube-mass spectrometer (SIFT-MS) (SYFT Voice200, Syft Ltd., Christchurch, New Zealand). Volatiles were measured by SIFT-MS by using kinetics parameters in (Table 1) during and after blending.

\begin{tabular}{|c|c|c|c|c|c|}
\hline Compound & $\begin{array}{l}\text { Precurso } \\
\text { r lon }\end{array}$ & $\begin{array}{l}\mathrm{k}(10-9 \\
\left.\mathrm{cm}^{3} / \mathrm{s}\right)\end{array}$ & $\mathrm{m} / \mathbf{z}$ & Product ion & Reference \\
\hline (E)-2-heptenal & $\mathrm{NO}^{+}$ & 3.9 & 111 & $\mathrm{C}_{7} \mathrm{H}_{11} \mathrm{O}^{+}$ & [16] \\
\hline (E)-2-hexenal & $\mathrm{NO}^{+}$ & 3.8 & 97 & $\mathrm{C}_{6} \mathrm{H}_{9} \mathrm{O}^{+}$ & [17] \\
\hline (E)-2-octenal & $\mathrm{NO}^{+}$ & 4.1 & 156 & $\mathrm{C}_{8} \mathrm{H}_{14} \mathrm{O}^{-\mathrm{NO}^{+}}$ & [16] \\
\hline (Z)-3-hexenal & $\mathrm{H}^{3} \mathrm{O}^{+}$ & 4.2 & 81 & $\mathrm{C}_{6} \mathrm{H}_{9}^{+}$ & [17] \\
\hline 1-hexanol & $\mathrm{NO}^{+}$ & 2.4 & 101 & $\mathrm{C}_{6} \mathrm{H}_{13} \mathrm{O}^{+}$ & [17] \\
\hline 1-penten-3-one & $\mathrm{NO}^{+}$ & 2.5 & 114 & $\mathrm{C}_{5} \mathrm{H}_{8} \mathrm{O}^{+} . \mathrm{NO}^{+}$ & [18] \\
\hline 2-pentenal & $\mathrm{NO}^{+}$ & 4.0 & 83 & $\mathrm{C}_{5} \mathrm{H}_{7} \mathrm{O}^{+}$ & [16] \\
\hline hexanal & $\mathrm{NO}^{+}$ & 2.5 & 99 & $\mathrm{C}_{6} \mathrm{H}_{11} \mathrm{O}^{+}$ & [17] \\
\hline hexanoic acid & $\mathrm{NO}^{+}$ & 2.5 & 146 & $\mathrm{C}_{6} \mathrm{H}_{12} \mathrm{O}_{2} \cdot \mathrm{NO}^{+}$ & [18] \\
\hline hexen-1-ol & $\mathrm{NO}^{+}$ & 2.5 & 72 & $\mathrm{C}_{4} \mathrm{H}_{8} \mathrm{O}^{+}$ & [18] \\
\hline hexenyl acetate & $\mathrm{NO}^{+}$ & 2.5 & 172 & $\mathrm{C}_{8} \mathrm{H}_{14} \mathrm{O}_{2} \cdot \mathrm{NO}^{+}$ & [18] \\
\hline hexyl acetate & $\mathrm{H}^{3} \mathrm{O}^{+}$ & 3.0 & 85 & $\mathrm{C}_{6} \mathrm{H}_{13}{ }^{+}$ & [18] \\
\hline
\end{tabular}

Table 1: Kinetic parameters of selected LOX volatile compounds for SIFT-MS analysis*. ${ }^{*}$-pentenal is a mixture of (E)-2-pentenal and
(Z)-2-pentenal. Hexen-1-ol is a mixture of (E)-3-hexen-1-ol and (Z)-3hexen-1-ol. Hexenyl acetate is a mixture of (Z)-3-hexenyl acetate and (E)-2-hexenyl acetate.

The environmental temperature of the SIFT-MS is between $23-24^{\circ} \mathrm{C}$ and the flow tube pressure is $0.05-0.08$ torr. Validations were run before scanning of samples. Hot water samples were run between every two scans of samples.

To study the effect of blending time on volatile concentration in the headspace, each sample was scanned for $40 \mathrm{~min}$. Blending was started immediately after the start of scan and continued for $0.5,1,3,5,10,15$, or $20 \mathrm{~min}$.

\section{Lipoxygenase activity}

To prepare samples, $100 \mathrm{~g}$ fruit were washed, dried and pureed in a blender ( 3 Cup Chopper, Oster, Boca Raton, FL, USA) for $30 \mathrm{~s}$. The puree was filtered through a cheese cloth to produce juice without seeds and peels. An aliquot of $1 \mathrm{ml}$ filtered juice was mixed with $396 \mu \mathrm{l}$ of $0.5 \mathrm{M}$ sodium phosphate buffer $\mathrm{pH} 6.5$ and $0.5 \%$ Triton X-100 in a $2.0 \mathrm{ml}$ microcentrifuge tube, and the mixture was centrifuged for 15 min at 10,000 $\times \mathrm{g}$ in an Eppendorf Centrifuge 5415R (Eppendorf N.A., Hauppauge, NY, USA) at $23^{\circ} \mathrm{C}$. The supernatant was removed and placed in a clean $2.0 \mathrm{ml}$ microcentrifuge tube as the enzyme extract [19].

The substrate solution was prepared by adding $70 \mathrm{mg}$ linoleic acid, $70 \mathrm{mg}$ Tween 20 , and $4 \mathrm{ml}$ distilled water to a $25 \mathrm{ml}$ flask. The solution was mixed by drawing in and out of a pasteur pipette and $0.6 \mathrm{ml}$ of 1.0 $\mathrm{N} \mathrm{NaOH}$ was added to clarify the solution. Then the overall solution was made up by adding distilled water to a total volume of $25 \mathrm{ml}$. The substrate solution was kept frozen until use.

The activity measurement was carried out by adding $2.7 \mathrm{ml}$ of $0.2 \mathrm{M}$ sodium phosphate buffer $\mathrm{pH} 6.5,30 \mu \mathrm{l}$ of substrate solution and $100 \mu \mathrm{l}$ of enzyme extract in a quartz cuvette at $25^{\circ} \mathrm{C}$. The change of absorption at $234 \mathrm{~nm}$ was recorded for $4 \mathrm{~min}$. The activity of lipoxygenase was determined by the slope of the linear part in the absorption-time curve. Five replicates were tested. Lipoxygenase activity was quantified as nmol of product formed per min on a fresh weight basis (nmol/g fwt $/ \mathrm{min}$ ). Free fatty acid content was determined from [20].

Data were analyzed by one-way analysis of variance (ANOVA) using the least significant differences for means (LSD). Significance was defined as $\mathrm{p} \leq 0.05$.

\section{Results and Discussion}

\section{Volatile aldehydes in the LOX pathway}

In the lipoxygenase (LOX) pathway, (Z)-3-hexenal, (E)-2-hexenal and hexanal are the first volatiles formed from free linolenic and linoleic acids by the action of lipoxygenase (LOX) and hydroperoxide lyase (HPL). (Z)-3-Hexenal is generated from linolenic acid, and has an intense spicy and grassy odor, characterized as a pleasant "green" aroma [21,22]. It has a low sensory threshold of detection concentration of $0.25 \mathrm{ppb}$ [21]. Thus, (Z)-3-hexenal in all of the samples in this study should be noticeable to consumers (Figure 1).

After tissue disruption, (Z)-3-hexenal concentration in fruits of the Solanaceae family (tomato, bell pepper, tomatillo) increased rapidly, 
Citation: Han Y and Barringer S (2016) Formation of Volatiles in the Lipoxygenase Pathway as Affected by Fruit Type and Temperature. J Exp

Page 3 of 7

and the maximum concentrations occurred within 5-10 min (Figure 1). In the first several minutes after fruit tissue disruption, (Z)-3hexenal was generated and accumulated due to enzyme activity. The rate of (Z)-3-hexenal release into the headspace of the fruit purees, which is determined by the rate of volatile generation and volatility, is higher than the rate of degradation and removal while sampling. The concentration of (Z)-3-hexenal then decreased rapidly as its rate of generation became lower than the rate of loss due to isomerization to (E)-2-hexenal, reductive conversion to (Z)-3-hexenol and transformation to hexanal $[23,24]$. The level of (Z)-3-hexenal may also decrease due to acetal type condensation with the sugars [23].

Fruits in the Rosaceae family (strawberry, apple, and pear) had lower ( $Z$ )-3-hexenal concentration than the fruits in the Solanaceae family and the concentration increased or remained constant, because the generation rate of $(\mathrm{Z})$-3-hexenal was higher than or the same as its degradation rate over the $60 \mathrm{~min}$ (Figure 1). Fruits in the Rosaceae family did not have clear peak concentrations of (Z)-3-hexenal.

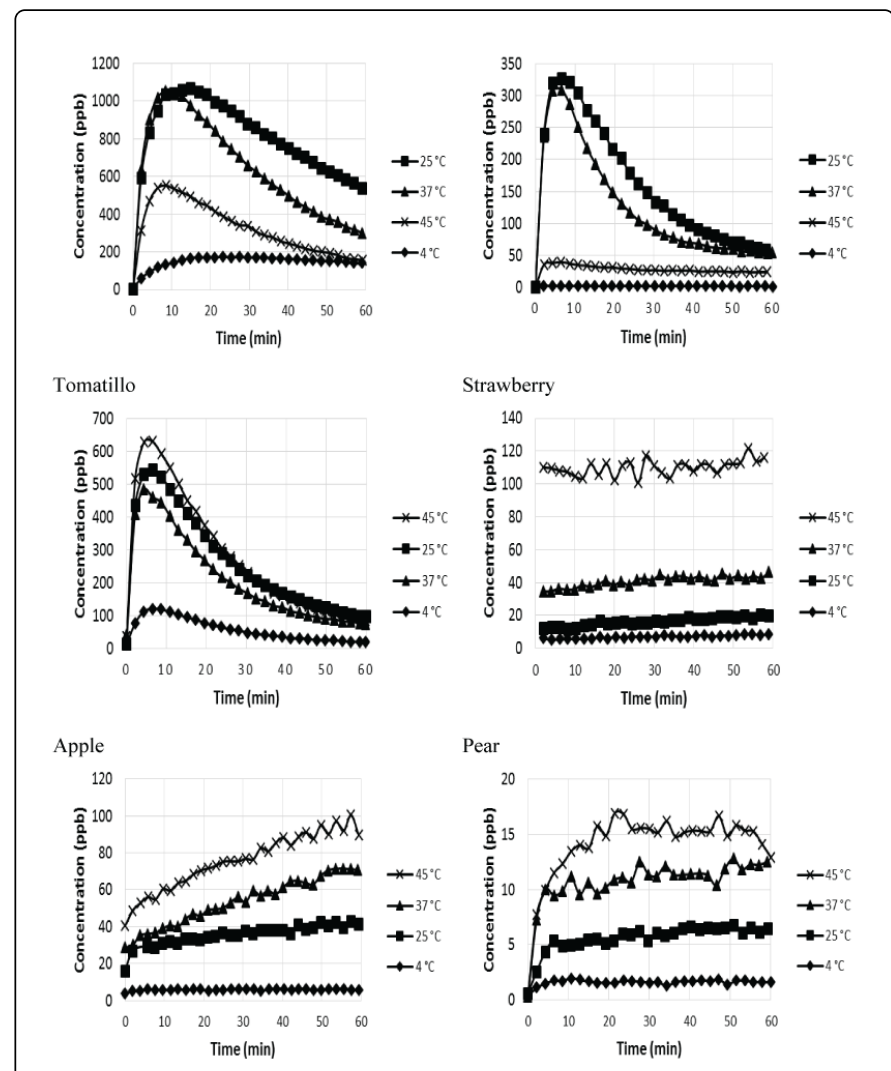

Figure1: Effect of temperature on concentration of (Z)-3-hexenal in the headspace of different fruits.

In all of the fruits, the highest LOX activity was at $25^{\circ} \mathrm{C}$ (Table 2). The lowest LOX activity occurred at $4^{\circ} \mathrm{C}$, followed by $45^{\circ} \mathrm{C}$. Similarly, it was reported that LOX activity increased from $0^{\circ} \mathrm{C}$ to $20^{\circ} \mathrm{C}$, reached its maximum activity at $20^{\circ} \mathrm{C}$ to $30^{\circ} \mathrm{C}$ and decreased at higher temperatures in tomato fruits $[6,7]$.

In tomato and bell pepper, (Z)-3-hexenal formation was greatest at $25^{\circ} \mathrm{C}$, which was also the temperature with the highest LOX activity (Figure 1, Table 2). In tomato and bell pepper, the peak concentration of (Z)-3-hexenal had good correlation to LOX activity across different temperatures, with R2 of 1.00 and 0.77 (Figure 2).

\begin{tabular}{|l|l|l|l|l|}
\hline Temperature $\left({ }^{\circ} \mathrm{C}\right)$ & 4 & 25 & 37 & 45 \\
\hline Tomato & $77^{\mathrm{c}}$ & $223^{\mathrm{a}}$ & $211^{\mathrm{a}}$ & $138^{\mathrm{b}}$ \\
\hline Bell pepper & $93^{\mathrm{c}}$ & $168^{\mathrm{a}}$ & $135^{\mathrm{b}}$ & $126^{\mathrm{b}}$ \\
\hline Tomatillo & $12^{\mathrm{b}}$ & $73^{\mathrm{a}}$ & $22^{\mathrm{b}}$ & $19^{\mathrm{b}}$ \\
\hline Strawberry & $22^{\mathrm{c}}$ & $56^{\mathrm{a}}$ & $41^{\mathrm{b}}$ & $35^{\mathrm{b}}$ \\
\hline Apple & $33^{\mathrm{c}}$ & $135^{\mathrm{a}}$ & $114^{\mathrm{b}}$ & $43^{\mathrm{c}}$ \\
\hline Pear & $11^{\mathrm{c}}$ & $26^{\mathrm{a}}$ & $25^{\mathrm{a}}$ & $19^{\mathrm{b}}$ \\
\hline
\end{tabular}

Table 2: Lipoxygenase (LOX) activity (nmols/g fwt/min) at different temperatures in tomato, bell pepper, tomatillo, strawberry, apple and pear $^{\text {a }}{ }^{a}$ Values with different letters in the same row are significantly different.

When LOX activity in tomato was decreased by reducing expression of LOX mRNA, the levels of hexenal ((Z)-3-hexenal plus (E)-2hexenal) and hexanal were significantly decreased [11]. Similarly, when LOX in bell pepper homogenates was inhibited by 5,8,11,14eicosatetraynoic acid, the levels of (Z)-3-hexenal, (E)-2-hexenal and hexanal decreased [13].

$$
\text { Tomato }
$$

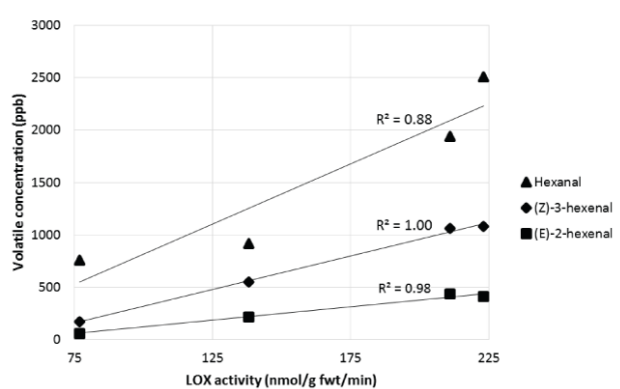

Bell pepper

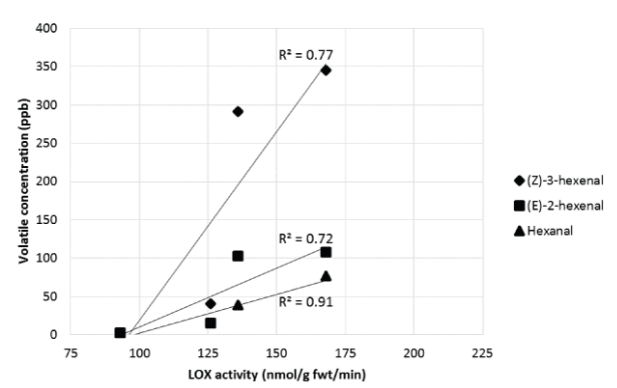

Figure 2: Correlation between lipoxygenase (LOX) activity and peak levels of (Z)-3-hexenal, (E)-2-hexenal and hexanal in tomato and bell pepper at $4 \mathrm{C}, 25 \mathrm{C}, 37 \mathrm{C}$ and $45 \mathrm{C}$.

(Z)-3-Hexenal is expected to correlate to LOX activity because LOX is the enzyme that catalyzes the oxidation of free linolenic acid to 9hydroperoxide and 13-hydroperoxide which is further converted to (Z)-3-hexenal by HPL. Thus, LOX plays an important role in the generation of (Z)-3-hexenal. On the other hand, in tomatillo, strawberry, apple and pear, (Z)-3-hexenal formation increased as 
temperature increased but its concentration had poor correlation with LOX activity (R2 lower than 0.54 ), indicating that factors other than LOX activity dominated control of the generation of (Z)-3-hexenal (Figure 1, Table 2). Tomato and bell pepper had much higher LOX activity levels than the other fruits at each temperature (Table 2). Because of its higher activity, LOX activity may have dominated over the other factors affecting (Z)-3-hexenal formation in tomato and bell pepper but not in the other fruits. Other important factors in measurement of the volatiles in the headspace are increased partition coefficient at higher temperature, because higher temperature gives volatile molecules more energy to escape from the medium into the air phase [25]. HPL activity is less likely to be a factor because it decreases from 25 to $45^{\circ} \mathrm{C}$ similar to LOX activity, in tomato [9]. Another factor to consider is that (Z)-3-hexenal may be rapidly converted into other volatiles such as esters, especially in the case of strawberry.

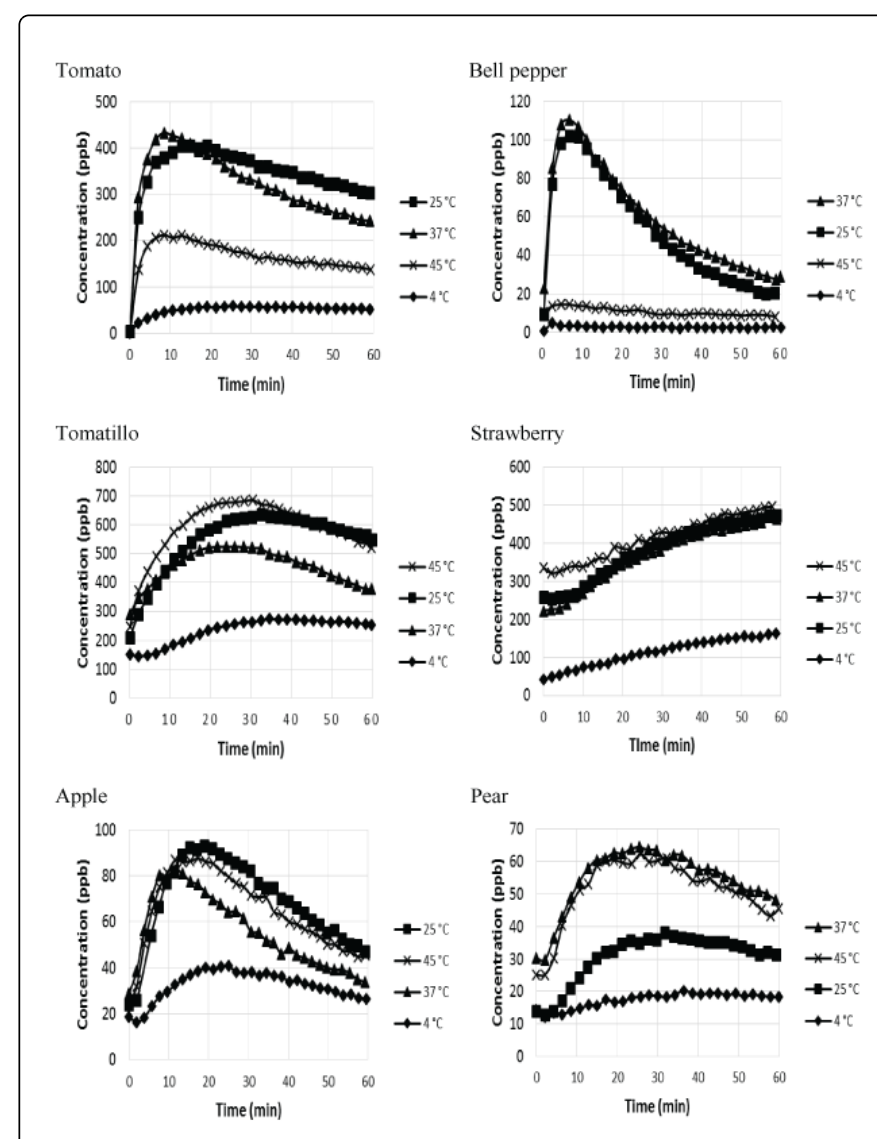

Figure 3: Effect of temperature on concentration of (E)-2-hexenal in the headspace of different fruits.

(E)-2-Hexenal is isomerized from (Z)-3-hexenal by (Z)-3/(E)-2 isomerase. The threshold of detection for (E)-2-hexenal is $30 \mathrm{ppb}$ [26], so (E)-2-hexenal should be noticeable to consumers in all samples except bell pepper at 4 and $45^{\circ} \mathrm{C}$ and in pear at $4^{\circ} \mathrm{C}$ (Figure 3). The aroma of (E)-2-hexenal is similar to (Z)-3-hexenal but less fresh "green" in character and less intense [21]. After tissue disruption, (E)-2-hexenal concentration in all fruits except strawberry increased, and reached maximum concentrations around 5-20 min (Figure 3). In strawberry and pear, the concentration of $(\mathrm{Z})$-3-hexenal is much lower than the concentration of (E)-2-hexenal, implying that the activity of (Z)-3/(E)-2 isomerase may be much higher in those fruits.
(E)-2-Hexenal had a similar temperature dependence as (Z)-3hexenal in most of the fruits, likely because the generation of (E)-2hexenal was greatly affected by the concentration of (Z)-3-hexenal present at different temperatures (Figure 3). Similar to (Z)-3-hexenal, there was a good correlation between the peak level of (E)-2-hexenal and LOX activity in tomato and bell pepper (R2 of 0.98 and 0.72 ), but not in tomatillo, strawberry, apple and pear.

Hexanal is generated from linoleic acid by LOX and HPL. It has been reported that $(\mathrm{Z})-3$-hexenal is also converted to hexanal but this conversion contributes to only $2 \%$ of total hexanal concentration in tomato [12]. Hexanal has a penetrating green, grassy odor with a low threshold of $4.5 \mathrm{ppb}$ [21]. Thus, hexanal in all fruits except bell pepper at $4^{\circ} \mathrm{C}$ should be noticeable to consumers (Figure 4). After tissue disruption, hexanal in all fruits except strawberry increased, reached maximum concentration and then decreased. After fruit tissue disruption, hexanal was generated due to enzymatic activity, then decreased due to reductive conversion to 1-hexanol and oxidation to hexanoic acid.

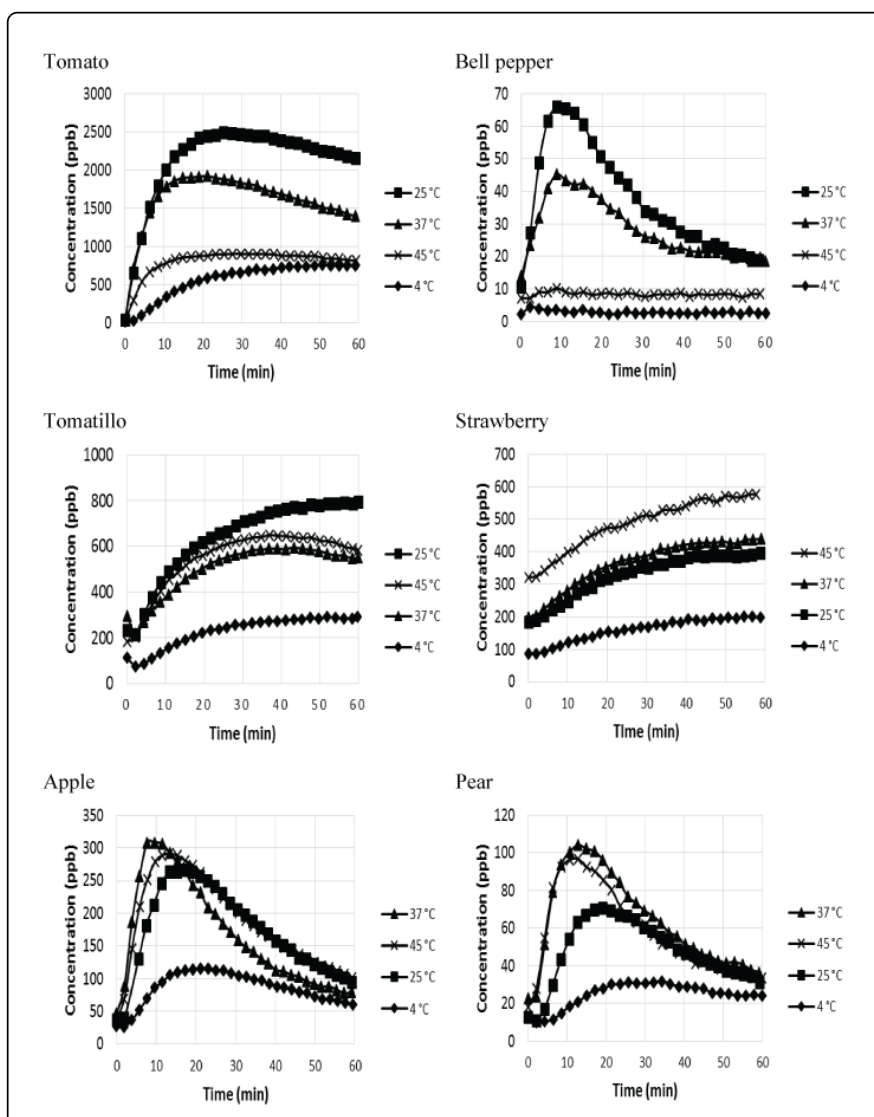

Figure 4: Effect of temperature on concentration of hexanal in the headspace of different fruits.

Similar to (Z)-3-hexenal and (E)-2-hexenal, the peak concentration of hexanal had good correlation to LOX activity (R2 of 0.88 and 0.91 ) in tomato and bell pepper, and poor correlation in tomatillo, strawberry, apple and pear (R2 lower than 0.51) (Figure 2). 
Citation: Han Y and Barringer S (2016) Formation of Volatiles in the Lipoxygenase Pathway as Affected by Fruit Type and Temperature. J Exp

\section{Volatile alcohols in the LOX pathway}

In the LOX pathway, alcohols are created from the corresponding aldehydes by ADH. Hexen-1-ol is formed from (Z)-3-hexenal and (E)-2-hexenal, and 1-hexanol is formed from hexanal. Hexen-1-ol has a "green" odor and a sensory threshold of $70 \mathrm{ppb}$ [21]. 1-Hexanol has a green, grassy note with a threshold of $200 \mathrm{ppb}$ (Burdock 2009). Thus, hexen-1-ol should be noticeable to consumers only in strawberry (Figure 5), while 1-hexanol should not be noticeable to consumers in any of these fruits (Figure 6). The alcohols are formed at much lower levels than the aldehydes in all fruits except for hexen-1-ol in strawberry. After tissue disruption, hexen-1-ol and 1-hexanol in all fruits increased gradually or remained constant over the $60 \mathrm{~min}$. Over time hexen-1-ol converts into (Z)-3-hexenyl acetate and (E)-2-hexenyl acetate, and 1-hexanol converts into hexyl acetate.

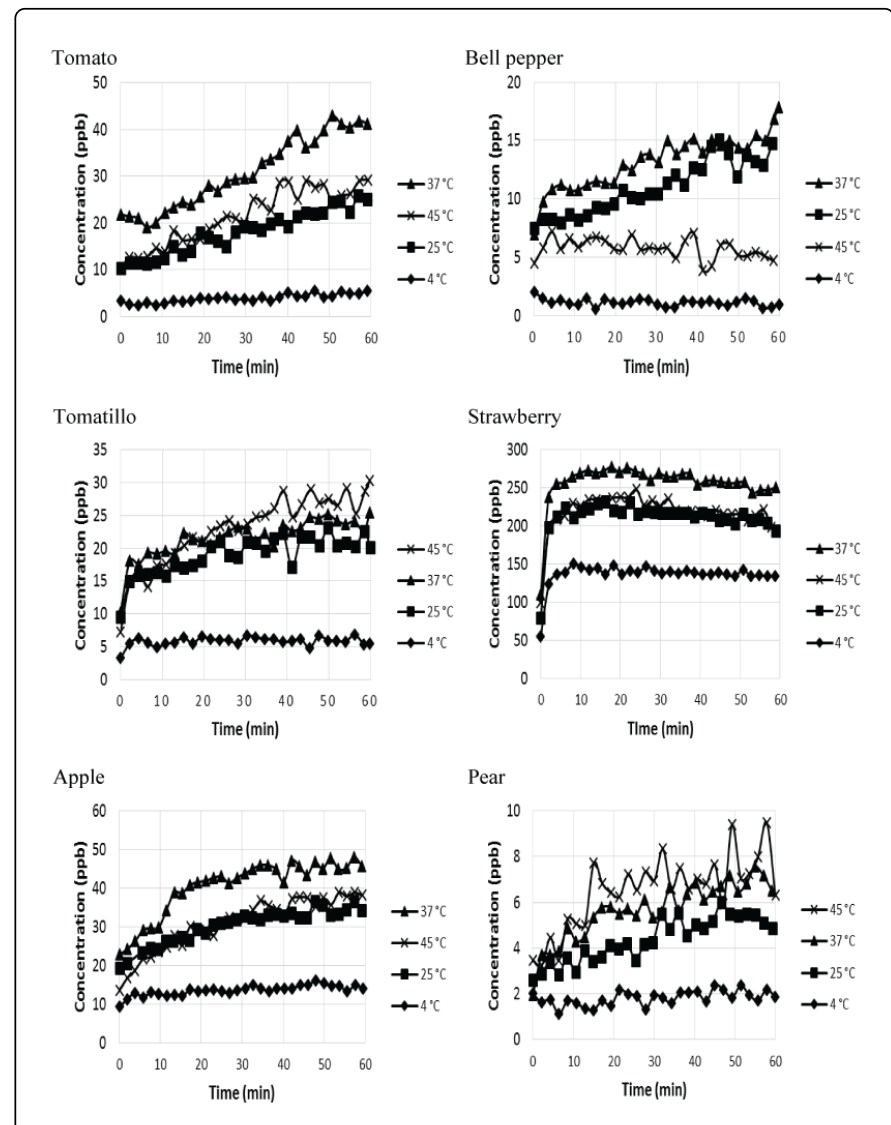

Figure 5: Effect of temperature on concentration of hexen-1-ol in the headspace of different fruits.

The concentrations of hexen-1-ol and 1-hexanol in the LOX pathway did not correlate to LOX activity for any of the fruits. In all fruits, $37^{\circ} \mathrm{C}$ produced the highest hexen-1-ol level though in some cases it was not significantly different from $45^{\circ} \mathrm{C}$ or $25^{\circ} \mathrm{C}$ (Figure 5). Since 25 and $45^{\circ} \mathrm{C}$ was often the temperature with highest concentrations of (Z)-3-hexenal and (E)-2-hexenal, the precursors for hexen-1-ol, ADH in fruits appears to have the greatest activity at $37^{\circ} \mathrm{C}$. $\mathrm{ADH}$ has been reported to have the highest activity at $35^{\circ} \mathrm{C}$ in brewer's yeast [27]

Similarly, in tomato and bell pepper, $37^{\circ} \mathrm{C}$ is the temperature with highest 1-hexanol level (Figure 6). In these two fruits, ADH may be the rate limiting factor for the generation of 1-hexanol. But in tomatillo, strawberry, apple and pear, the volatile concentration increased with temperature. In these four fruits, increased partition coefficient at higher temperature likely had a greater influence on the concentrations of 1-hexanol.

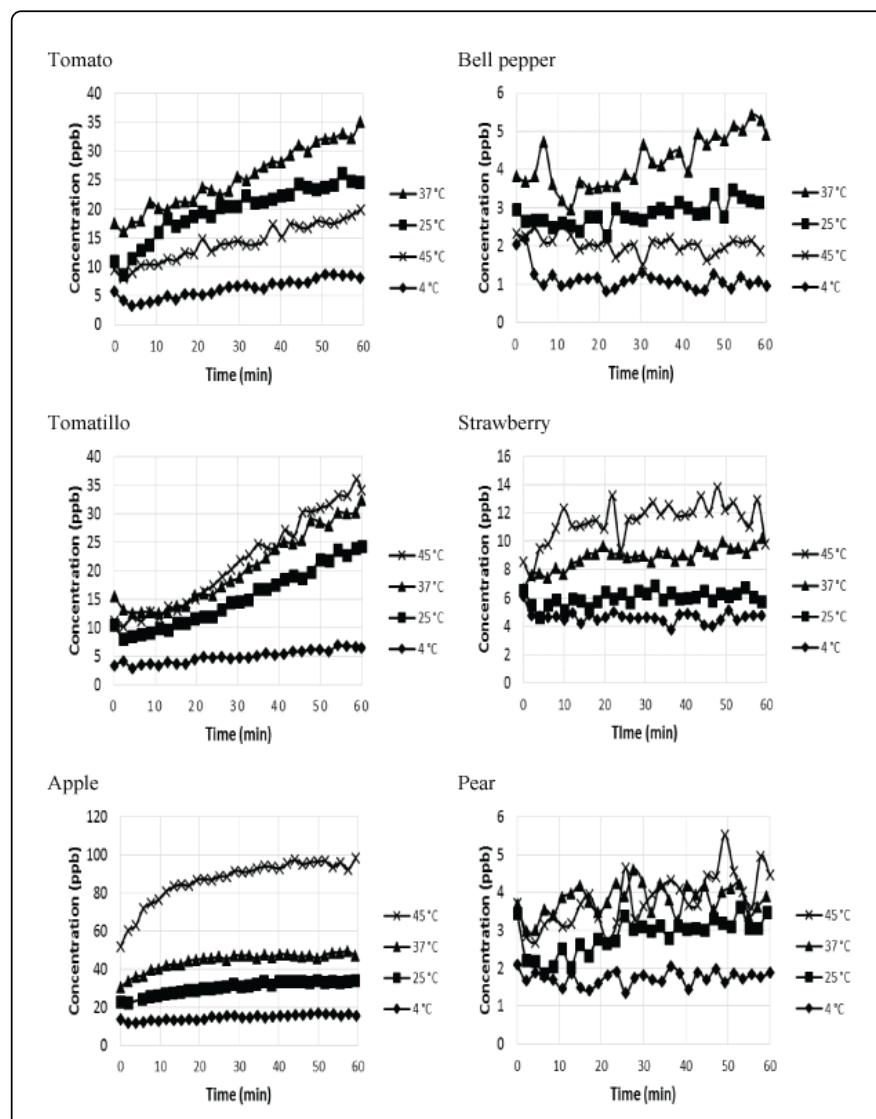

Figure 6: Effect of temperature on concentration of 1-hexanol in the headspace of different fruits.

\section{Other volatiles}

The other volatiles generated from the LOX pathway were generally at low concentration and increased as temperature increased. The exception was hexanoic acid, hexenyl acetate and hexyl acetate in the Rosacea family, strawberry, pear and apple. Hexanoic acid is formed from either the 13-hydroperoxide of linoleic acid or hexenal by oxidation $[28,29]$. Hexenyl and hexyl acetate are formed from hexen-1ol or 1-hexanol and acetic acid. These three volatiles contribute fruity notes and are formed at significant concentrations in strawberry, pear and apple. Compared to other fruits, strawberry had higher concentrations of hexenyl acetate, likely because strawberry had higher concentration of hexen-1-ol which is the precursor for hexenyl acetate.

\section{Effect of fatty acid concentration on volatile concentration}

Linolenic and linoleic acids are substrates for the LOX pathway. Linolenic acid is the precursor of (Z)-3-hexenal and linoleic acid is the precursor of hexanal. Thus, linolenic and linoleic acid contents also play an important role in volatile generation in the LOX pathway. The linoleic acid:linolenic acid ratio in cherry and Solairo tomatoes is 1.75 
and 4.1, and the ratios of peak levels of hexanal:hexenal (the combination of (Z)-3-hexenal and (E)-2-hexenal) is 0.1 and 0.27 , respectively [30]. Thus, it appears that a higher ratio of linoleic acid:linolenic results in a higher ratio of hexanal:hexenal. An increase of hexanal upon addition of linoleic acid and an increase of (Z)-3hexenal and (E)-2-hexenal upon addition of linolenic acid have also been reported in tomato [3,12], bell pepper [13] and cucumber [14]. However, there was no strong correlation between the ratio of linoleic acid:linolenic acid and the ratio of hexanal:hexenal in the Solanaceae family (R2=0.65) (Table 3).

\begin{tabular}{|l|l|l|l|l|}
\hline & $\begin{array}{l}\text { Linoleic } \\
\text { acid (g/ } \\
\mathbf{1 0 0 g} \\
\mathbf{f w t})\end{array}$ & $\begin{array}{l}\text { Linoleni } \\
\mathbf{c} \mathbf{a c i d} \\
\mathbf{( g / 1 0 0 g} \\
\mathbf{f w t})\end{array}$ & $\begin{array}{l}\text { Ratio of } \\
\text { linoleic acid/ } \\
\text { linolenic acid }\end{array}$ & $\begin{array}{l}\text { Ratio of hexanal/ } \\
\text { hexenal }^{*}\end{array}$ \\
\hline Tomato & 0.08 & 0.003 & 26.67 & 1.69 \\
\hline Bell pepper & 0.054 & 0.008 & 6.75 & 0.15 \\
\hline Tomatillo & 0.402 & 0.016 & 25.13 & 0.68 \\
\hline Strawberry & 0.09 & 0.065 & 1.38 & 0.8 \\
\hline Apple & 0.043 & 0.009 & 4.78 & 1.97 \\
\hline Pear & 0.093 & 0.001 & 93 & 1.6 \\
\hline
\end{tabular}

Table 3: Linoleic acid and linolenic acid content in tomato, bell pepper, tomatillo, strawberry, apple and pear. ${ }^{*}$ Hexenal was the sum of (Z)-3hexenal and (E)-2-hexenal. Hexanal and hexenal concentrations are their maximum concentrations over $60 \mathrm{~min}$ at $25^{\circ} \mathrm{C}$.

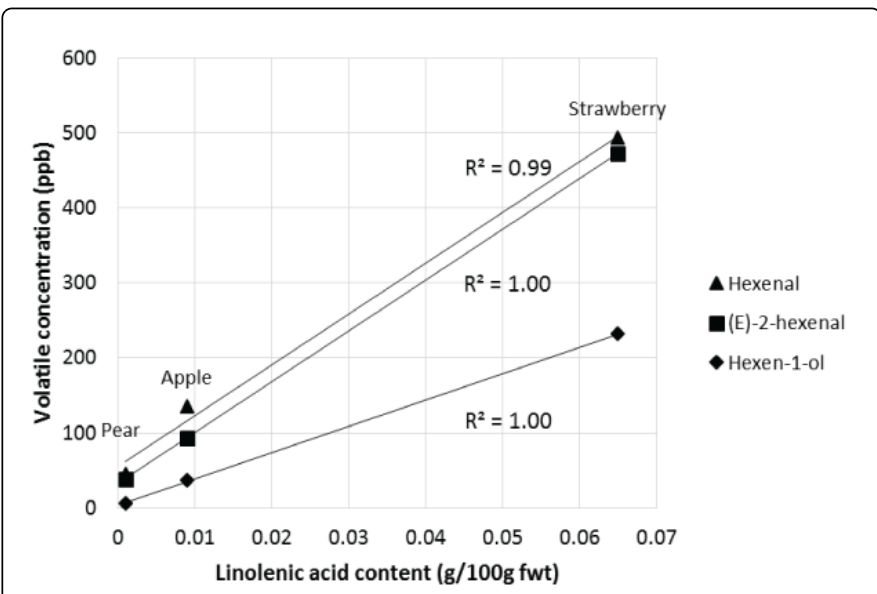

Figure 7: Correlation between maximum concentrations of (E)-2hexenal, hexenal and hexen-1-ol and linolenic acid content in strawberry, apple and pear at $25^{\circ} \mathrm{C}$.

In the Rosaceae family (strawberry, apple and pear), there were good correlations between linolenic acid content and concentrations of (E)-2-hexenal $(\mathrm{R} 2=1.00)$, hexenal (sum of $(\mathrm{Z})$-3-hexenal and (E)-2hexenal) $(\mathrm{R} 2=0.99)$ and hexen-1-ol (sum of (Z)-3-hexenol and (E)-2hexenol) $(\mathrm{R} 2=1.00)$ (Figure 7), indicating linolenic acid content might be the rate limiting factor for the formation of (E)-2-hexenal, hexenal and hexen-1-ol in these fruits. However, there was no correlation between linolenic acid content and (E)-2-hexenal, hexenal and hexen-1-ol in the Solanaceae family (tomato, bell pepper and tomatillo). Also, linoleic acid content did not correlate to hexanal or 1hexanol in any fruit.

\section{Effect of blending time on volatile concentration}

(Z)-3-Hexenal is typical of the behavior of the lipoxygenase (LOX) generated volatiles in tomatoes in response to tissue disruption and is shown as a representative volatile (Figure 8). Continual blending resulted in volatile levels constantly increasing in the headspace, and therefore higher volatile concentrations were found at the end of longer blending times. However, the volatile levels decreased significantly once blending stopped, after blending for more than 5 min, indicating that the blending process was creating artificially high volatile levels. After blending for less than $3 \mathrm{~min}$, the concentration continued to increase after blending stopped, before later decreasing, as would be expected. The levels of LOX volatiles increase greatly after cell rupture [32]. Compared to sliced tomatoes, blended tomatoes had higher concentrations for most LOX generated volatiles, indicating the concentrations of LOX volatiles increase when the degree of tissue rupture is increased [33]. However, the decline in volatile levels following longer blending times indicates that the longer blending times were increasing volatile levels more because of increasing the partition coefficient, then due to tissue disruption.

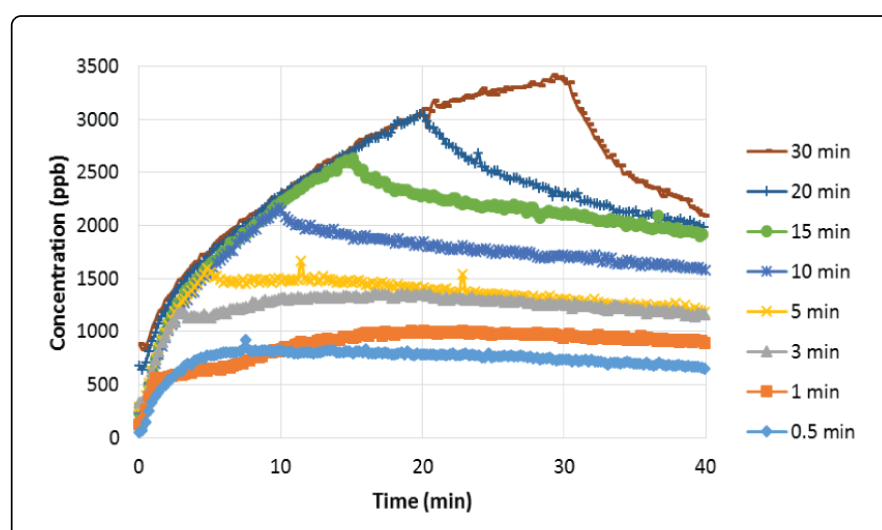

Figure 8: Effect of blending time on concentrations of (Z)-3-hexenal in the headspace of tomato.

The proper blending time for this study was determined to be $30 \mathrm{~s}$. A shorter blending time ensures less effect of blending on the air-liquid ratio partition co-efficient [31]. In addition, blending for $30 \mathrm{~s}$ for better mimics tomato breakdown in the mouth than longer blending times.

\section{Conclusion}

LOX activity was a good predictor of (Z)-3-hexenal, (E)-2-hexenal and hexanal formation in tomato, bell pepper and tomatillo, but was not a good predictor for the other volatiles, or for strawberry, apple and pear. Linolenic acid had a good correlation to (E)-2-hexenal, hexenal and hexen-1-ol formation in strawberry, apple and pear, but not in tomato, bell pepper and tomatillo, and neither linoleic acid nor the linoleic acid:linolenic acid ratio had good correlations to the other volatiles. Thus the effect of enzyme activity and substrate composition on formation of volatiles in the lipoxygenase pathway remains complicated and difficult to predict.

There were some family differences between the fruits in the Rosaceae family (strawberry, apple, and pear) and the Solanaceae 
family (tomato, bell pepper, tomatillo), but generalizations are difficult to make. Some of the initial volatiles formed in the pathway that are most associated with fresh notes, such as (Z)-3-hexenal and (E)-2hexenal, are highest in the Solanaceae family (tomato, bell pepper, tomatillo) while the esters and other volatiles formed later in the pathway, such as hexanoic acid, (Z)-3-hexenyl acetate and hexyl acetate, are higher in the Rosaceae family (strawberry, apple, and pear).

\section{References}

1. Schwab W, Davidovich-Rikanati R, Lewinsohn E (2008) Biosynthesis of plant-derived flavor compounds. Plant J 54: 712-732.

2. Ho CT, Chen Q (1994) Lipids in Food Flavors. In: Ho CT, Hartman TG, editors. Lipids in food flavors. Washington, DC: American Chemical Society, pp. 30-48.

3. Galliard T, Matthew JA (1977) Lipoxygenase-mediated cleavage of fatty acids to carbonyl fragments in tomato fruits. Phytochemistry 16: 339-343.

4. Tsachaki M, Gady AL, Kalopesas M, Linforth RS, Athe's V, et al. (2008) Effect of ethanol, temperature, and gas flow rate on volatile release from aqueous solutions under dynamic headspace dilution conditions. J Agricult Food Chem 56: 5308-5315.

5. van Ruth SM, Roozen JP (2009) In: Taylor AJ (ed.) Delivery of flavours from food matrices. Food Flavour Technology, Sheffield Academic Press., Sheffield, UK, pp. 167-184.

6. Jadhav S, Singh B, Salunkhe DK (1972) Metabolism of unsaturated fatty acids in tomato fruit: linoleic and linolenic acid as precursors of hexanal. Plant Cell Physiol 13: 449-459.

7. Yilmaz E (2001) Oxylipin pathway in the biosynthesis of fresh tomato volatiles. Turk J Biol 25: 351-360.

8. Bai J, Baldwin EA, Imahori Y, Kostenyuk I, Burns J, et al. (2011) Chilling and heating may regulate $\mathrm{C} 6$ volatile aroma production by different mechanisms in tomato (Solanum lycopersicum) fruit. Postharvest Biol Tec 60: 111-120.

9. Rodrigo D, Jolie R, Loey AV, Hendrickx M (2007) Thermal and high pressure stability of tomato lipoxygenase and hydroperoxide lyase. J Food Eng 79: 423-429.

10. León-Sánchez FD, Pelayo-Zaldívar C, Rivera-Cabrera F, Ponce-Valadez M, Ávila-Alejandre X, et al. (2009) Effect of refrigerated storage on aroma and alcohol dehydrogenase activity in tomato fruit. Postharvest Biol Tec 54: 93-100.

11. Chen G, Hackett R, Walker D, Taylor A, Lin Z, et al. (2004) Identification of a specific isoform of tomato lipoxygenase (TomloxC) involved in the generation of fatty acid-derived flavor compounds. Plant Physiol 136: 2641-2651.

12. Stone EJ, Hall RM, Kazeniac SJ (1975) Formation of aldehydes and alcohols in tomato fruit from U-14 C-labeled linolenic and linoleic acids. J Food Sci 40: 1138-1141.

13. Luning PA, Carey AT, Roozen JP, Wichers HJ (1995) Characterization and occurrence of lipoxygenase in bell peppers at different ripening stages in relation to the formation of volatile flavor compounds. J Agric Food Chem 43: 1493-1500.

14. Grosch W, Schwarz JM (1971) Linoleic and linolenic acid as precursors of the cucumber flavor. Lipids 6: 351-352.
15. Gould WA, Gould RW (2001). Total Quality Assurance for the Food Industries. CTI Publications Inc. Timonium MD, p. 357.

16. Spanel V, Doren, Smith D (2002) A selected ion flow tube study of the reactions of $\mathrm{H} 3 \mathrm{O}+, \mathrm{NO}+$, and $\mathrm{O} 2+$ with saturated and unsaturated aldehydes and subsequent hydration of the product ions. Int J Mass Spectrom 213: 163-176.

17. Spanel P, Ji Y, Smith D (1997) SIFT studies of the reactions of $\mathrm{H} 3 \mathrm{O}+$, NO + , and $\mathrm{O} 2+$ with a series of aldehydes and ketones. Int J Mass Spectrom 165/166: 25-37.

18. Syft Technologies (2009). Kinetic library database. Christchurch, New Zealand: Syft Technologies Inc.

19. Ties P, Barringer S (2012) Influence of lipid content and lipoxygenase on flavor volatiles in the tomato peel and flesh. J Food Sci 77: C830-837.

20. U.S. Department of Agriculture, Agricultural Research Service (2014). USDA National Nutrient Database for Standard Reference. Release 27. Nutrient Data Laboratory Home Page.

21. Petro-Turza M (1986) Flavor of tomato and tomato products. Food Rev Int 2: 309-351.

22. Zhuang H, Barth MM, Hildebrand D (2002). Fatty acid oxidation in plant lipids. In Food Lipids, Chemistry, Nutrition and Biotechnology (Akoh, C.C. and Min, D.B., eds.), Marcel Dekker, Inc., New York, NY, pp. 413464 .

23. Buttery RG, Ling LC (1993) Volatiles of tomato fruit and plant parts: Relationship and biogenesis. Bioactive volatile compounds from plants. Washington DC: American Chemical Society, pp. 23-34.

24. Xu Y, Barringer S (2009) Effect of temperature on lipid-related volatile production in tomato puree. J Agric Food Chem 57: 9108-9113.

25. Hall G, Andersson J (1983) Volatile fat oxidation products. II. Influence of temperature on volatility of saturated, mono-and di-unsaturated aldehydes in liquid media. Food Sci Technol-Leb 16: 362-366.

26. Burdock GA (2009) Fenaroli's handbook of flavor ingredients. 6th ed. New York: CRC press, pp. 803-1609.

27. Zhao Q, Hou Y, Gong GH, Yu MA, Jiang L, et al. (2010) Characterization of alcohol dehydrogenase from permeabilized brewer's yeast cells immobilized on the derived attapulgite nanofibers. Appl Biochem Biotechnol 160: 2287-2299.

28. De Pooter HL, Schamp NM (1989) Involvement of lipoxygenasemediated lipid catabolism in the start of the autocatalytic ethylene production by apples (cv Golden Delicious): A Ripening Hypothesis. Acta Horticulture. 258: 47-53.

29. Reineccius G (2005). Flavor formation in fruits and vegetables. In: Reineccius G, (ed.) Flavor Chemistry and Technology, Second Edition. Florida. CRC Press, pp. 73-98.

30. Gray DA, Prestage S, Linforth RS, Taylor AJ (1999) Fresh tomato specific fluctuations in the composition of lipoxygenase-generated C6 aldehydes. Food Chem 64: 149-155.

31. Boukobza F, Dunphy PJ, Taylor AJ (2001) Measurement of lipid oxidation-derived volatiles in fresh tomatoes. Postharvest Biol Tech 23: 117-131.

32. Baldwin EA, Scott JW, Shewmaker CK, Schuch W (2000) Flavor trivia and tomato aroma: biochemistry and possible mechanisms for control of important aroma components. HortScience 35: 1013-1022.

33. Buttery RG, Teranishi R, Ling LC (1987) Fresh tomato aroma volatiles: a quantitative study. J Agric Food Chem 35: 540-544. 